Motrivivência Ano XXV, No 40, P. 80-89 Jun./2013

http://dx.doi.org/10.5007/2175-8042.2013v25n40p80

\title{
FORMAÇÃO INICIAL E CONTINUADA DE DOCENTES DE EDUCAÇÃO FÍSICA ATUANTES NA MODALIDADE DE EDUCAÇÃO ESPECIAL
}

\author{
Robson Frank \\ Jeferson Stocco ${ }^{2}$ \\ Douglas Roberto Borella ${ }^{3}$ \\ Jalusa Andréia Storch ${ }^{4}$ \\ Angela Schone ${ }^{5}$
}

\section{RESUMO}

Este estudo objetivou identificar o perfil dos professores de Educação Física que atuam no ambiente escolar na modalidade de Educação Especial, no que tange à formação inicial e continuada relacionada às pessoas com deficiência. Utilizou-se da abordagem exploratória e descritiva, de natureza quantitativa. Diante dos resultados angariados, acredita-se que os professores de Educação Física que atuam em modalidades de Educação Especial tem a possibilidade de explorar em escalas muito maiores o seu campo de atuação e construção de saber, por meio da continuidade de sua formação profissional e junto a isto, compartilhando seus conhecimentos e experiências profissionais com demais pessoas interessadas neste campo.

Palavras-chave: Formação; Professores; Educação Física; Pessoas com Deficiência; Educação Especial.

1 Graduando em Educação Física. Bolsista Pibic/CNPq/Universidade Estadual do Oeste do Paraná. Toledo/Paraná, Brasil. E-mail: robson frank91@hotmail.com.

2 Licenciado em Educação Física. Universidade Estadual do Oeste do Paraná. Toledo/Paraná, Brasil. E-mail: stocco.j@hotmail.com.

3 Docente na Universidade Estadual do Oeste do Paraná. Toledo/Paraná, Brasil.

E-mail: douglasedufisica@yahoo.com.br.

4 Doutoranda do Programa de Pós Graduação em Educação Física. Faculdade de Educação Física da Universidade Estadual de Campinas. Campinas/São Paulo, Brasil. E-mail: jalusastorch@yahoo.com.br.

5 Graduanda em Educação Física. Bolsista Pibic/CNPq/ Universidade Estadual do Oeste do Paraná. Toledo/ Paraná, Brasil. E-mail: angela_schone@hotmail.com. 


\section{INTRODUÇÃO}

A temática acerca da formação de professores em Educação Física é uma questão pontuada por dificuldades, não somente devido a diversidade de opiniões ou aspectos legais vinculados a esta formação, como também a pluralidade de atuações que nela incidem. No contexto educacional da área verifica-se certa heterogeneidade nas propostas de métodos de ensino, perspectivas teóricas, diferenciações curriculares e práticas corporais, cujas temáticas influenciam diretamente a formação inicial (licenciados ou bacharéis) e continuada dos docentes.

Sabe-se que a formação docente percorre toda a vida profissional, sendo considerada como algo inacabado e processual. Este processo envolve uma série de influências que vão desde os aspectos familiares, os vários anos nos bancos escolares, o curso de graduação, a atuação profissional enquanto docente e o posterior aprimoramento na área, sendo que todos estes momentos contribuem para a construção de imagens, crenças, idéias, conhecimentos e saberes sobre o ensinar e o que é ser professor e que constituem (e vão continuar constituindo) o docente, oferecendo-nos a ideia de um processo contínuo e permanente.

Tardif (2002) menciona que a arte de "professorar" não é uma atividade burocrática para a qual simplesmente se adquire conhecimentos e habilidades técnico-mecânicas. Acima de tudo existe a necessidade de que o professor se atualize permanentemente, pois conforme relata
Demo (2004, p. 121) "se o conhecimento, de um lado, é aquilo que a tudo inova, do outro lado da mesma moeda é aquilo que a tudo envelhece".

Seguindo este raciocínio, o professor de Educação Física (assim como os demais professores) não pode estar desconectado desta realidade e deve prosseguir com a construção de novos saberes a partir de reflexões individuais e coletivas advindas tanto de sua formação inicial quanto na continuada.

Considera-se que a formação inicial visa à preparação integral do futuro profissional para atuar na área por ele escolhida, disponibilizando conhecimentos e experiências sólidas que possam minimizar o risco de equívocos futuros na condição como docente. Em relação aos cursos de licenciatura, a formação inicial deve ser dotada de elementos teóricos, metodológicos e técnicos indispensáveis para o desenvolvimento de práticas exitosas no âmbito escolar ${ }^{6}$ para a formação de alunos "críticos, inovadores, autônomos, curiosos, investigativos", de modo que a aprendizagem permita a criação, expressão de valores e conhecimentos (DENARI, p. 221, 2008).

Já a preocupação com a formação continuada de professores de Educação Física reside-se no fato de que a sociedade está em constante transformação, onde a todo o momento nos diferentes contextos de atuação, dentre eles o ambiente escolar, são exigidos novos sistemas organizacionais que demandam inovações nas adaptações educacionais e formativas para todos os alunos, inclusive para aqueles com deficiência,

6 Ao mencionar âmbito escolar referimo-nos especificamente a etapa da Educação Básica, a qual compreende a Educação Infantil, o Ensino Fundamental e o Ensino Médio (BRASIL, 1996, Lei nº 9.394/96). 
os quais, em alguns momentos ou situações, necessitam de didáticas, recursos, diferenciadas de acordo com suas necessidades, exigindo transformação no modo de pensar e agir dos docentes frente às suas ações. É importante frisar que no atual contexto social e escolar brasileiro e até internacional, muitos alunos com deficiência encontram dificuldades para exercer seus direitos enquanto cidadãos, devido a uma série de barreiras atitudinais, arquitetônicas e até aquelas que envolvem o saber e o fazer dos profissionais.

Fazendo menção às escolas na modalidade de Educação Especial, as quais se destinam ao processo de ensino-aprendizagem de aluno com deficiência, o propósito do docente de Educação Física nestas escolas é de identificar as necessidades e capacidades do aluno com deficiência, procurando atender às possibilidades e adaptações para o movimento, visando facilitar a independência, autonomia e a inserção no processo de inclusão sócio-escolar (CIDADE e FREITAS, 1997).

Borella (2010) ressalta que neste processo de identificação deve-se levar em conta as adequações curriculares, a seleção dos materiais educativos, o apoio da equipe escolar e a correta eleição de estratégias metodológicas/didáticas que correspondam às necessidades e anseios de todos os alunos. A fim de atender a estes casos, verifica-se que tanto a formação inicial quanto continuada dos profissionais de Educação Física necessita de ajustes relacionados à realização de suas práticas junto a esta parcela da população.

Apesar de evidenciar avanços no que tange as preocupações acerca do aluno com deficiência, percebe-se que a formação profissional em Educação Física ainda apresenta limitações, principalmente quando nos questionamos sobre os conhecimentos dos profissionais adquiridos tanto ao longo de sua formação inicial quanto da continuada, os quais servem como alicerce para promover a prática docente compatível com as necessidades dos alunos com deficiência, e ao mesmo tempo, cujo conhecimento permite que o profissional esteja capacitado para diferenciar-se em seu campo de atuação.

Partindo destas reflexões, o presente estudo pautou-se na tarefa de identificar o perfil dos professores de Educação Física que atuam em escolas na modalidade de Educação Especial, no que concerne a formação inicial e continuada destes profissionais atrelada aos saberes relacionados às pessoas com deficiência.

\section{MÉTODO}

A fim de responder ao objetivo proposto deste estudo, optou-se pela utilização da pesquisa de campo, exploratória e descritiva, de natureza quantitativa (THOMAS, NELSON e SILVERMAN, 2007). A amostra foi composta por dez (10) professores de Educação Física atuante em escolas na modalidade de Educação Especial, localizadas na região da cidade de Foz do Iguaçu - PR, sendo seis (06) profissionais do gênero feminino e quatro (04) do gênero masculino, com idades entre 24 a 47 anos.

Como instrumento de coleta de dados utilizou-se de um questionário que buscou identificar as características de formação inicial e continuada dos professores de Educação Física, sendo desenvolvido e validado por Araújo (1999), composto de perguntas abertas e fechadas, o qual sofreu 
algumas alterações visando atender as necessidades desta pesquisa.

Quanto aos procedimentos para coleta de dados adotados, primeiramente buscou-se obter o endereço das escolas na modalidade de Educação Especial das cidades pertencentes à região de Foz do Iguaçu/PR, onde foram enviadas cartas convites para 20 escolas. Porém, ocorreu que parte dos endereços eletrônicos (e-mails) não estavam mais sendo utilizados pelas escolas, dificultando assim o processo de identificação dos professores atuantes em cada estabelecimento.

Diante disto, realizou-se o contato direto com os responsáveis de tais escolas, para em seguida ser adquirido o endereço de e-mail e número telefônico de cada professor de Educação Física que trabalhava na respectiva escola. Após o conhecimento destes dados, os pesquisadores apresentaram aos professores uma carta explicativa contendo os objetivos da pesquisa e juntamente encaminhado o Termo de Consentimento Livre e Esclarecido (TCLE) da pesquisa, onde deveria imprimir, assinar e retornar. Com o retorno da assinatura do TCLE, foi enviado via endereço eletrônico (e-mail) dos professores um questionário a ser respondido e posteriormente devolvido aos pesquisadores.

As respostas obtidas no instrumento de coleta foram analisadas quantitativamente por meio do aplicativo Microsoft Excel 2007, onde elaborou-se planilhas eletrônicas para tabulação e categorização dos resultados.

\section{RESULTADOS E DISCUSSÃO DOS DADOS}

As respostas obtidas por meio do instrumento de pesquisa discutirão o processo de formação inicial e continuada dos professores de Educação Física atuantes na modalidade de Educação Especial, cujos itens serão apresentados a seguir.

Quanto à ordem administrativa das instituições de formação inicial

A primeira questão buscou identificar a ordem administrativas das Instituições de Ensino Superior (IES) cursadas pelos professores de Educação Física ao longo de sua graduação. Os resultados revelaram que 20\% dos profissionais concluíram a graduação em IES estaduais e $80 \%$ em privadas, sendo que todos os professores obtiveram a titulação de licenciados em Educação Física, porém, há a possibilidade destes serem formados anteriormente à divisão das titulações de licenciatura e bacharelado em Educação Física.

No estado do Paraná observa-se, atualmente, contraste em relação às categorias administrativas das IES que oferecem a graduação em Educação Física - modalidade de Licenciatura. Segundo dados do E-MEC (2011), nove (09) IES são de ordem públicas, sendo uma (01) IES Federal (UFPR ${ }^{7}$ ) e seis (06) Estaduais (UNIOESTE ${ }^{8}$; UEPG ${ }^{9}$; UEL ${ }^{10}$; UEM $^{11}$; UNICENTRO $^{12}$; FAEFISA ${ }^{13}$ ). Em contrapartida, 25 IES privadas oferecem o curso de licenciatura em Educação Física em todo o Paraná.

$7 \quad$ Universidade Federal do Paraná;

8 Universidade Estadual do Oeste do Paraná;

9 Universidade Estadual de Ponta Grossa;

10 Universidade Estadual de Londrina;

11 Universidade Estadual de Maringá;

12 Universidade Estadual do Centro-Oeste;

13 Faculdade Estadual de Educação Física de Jacarézinho. 
Com base nestas informações, é possível averiguar que a demanda por procura de cursos em Educação Física vem aumentado significativamente no estado do Paraná, visto a crescente oferta de cursos oferecidos em IES privadas. Acredita-se que tal fato deva-se a um maior conforto, justamente pelas universidades localizarem-se mais próximas dos domicílios de acadêmicos, pelo valor mensal acessível, além dos investimentos no que concerne a estrutura física e material que os cursos privados disponibilizam aos seus acadêmicos.

Quanto às disciplinas voltadas às pessoas com deficiência durante a formação inicial

Quando questionados sobre o contato com disciplinas voltadas às pessoas com deficiência ao longo da graduação, verificou-se que todos os participantes destacaram apresentar nas matrizes curriculares de seus cursos disciplinas que trataram da pessoa com deficiência. Os envolvidos na pesquisa nomearam as diferentes nomenclaturas atribuídas nas ementas das disciplinas, tais como: Deficiências múltiplas e adaptação nas aulas de Educação Física; Educação Física Adaptada; Educação Física e Esportes Adaptados; Deficiência Mental Neurologia; Fundamentos teoria e educação psicomotora; Psicomotricidade; Prática da Educação Especial; Educação Especial; e, Metodologia da Educação Especial.

Vale salientar a importância de disciplinas que contemplam o conhecimento relacionado às pessoas com deficiência na formação inicial em Educação Física, principalmente quando aliado o conhecimento teórico com as experiências práticas. Acredita-se que o contato com esta população faz-se muito importante ao longo da vivência acadêmica, a fim de que o acadêmico quebre as barreiras, preconceitos, crenças e medos enquanto futuros profissionais que possivelmente vivenciarão ao longo de sua trajetória docente a experiência com alunos com alguma deficiência, os quais certamente necessitarão de uma visão diferenciada para a correta aplicação de métodos pedagógicos visando à inclusão no contexto das aulas.

Além disto, a literatura aponta certo consenso entre os termos Educação Física e Atividade Física, sendo que opta-se pela adoção do termo Educação Física quando as atividades são desenvolvidas no contexto escolar e Atividade Física quando tratam-se de atividades realizadas com objetivos não escolares, sendo que o termo Atividade Física Adaptada abarca conhecimentos da Educação Física e área afins, envolvendo as pessoas com deficiência (PEDRINELLI, 1994; BORELLA, 2010).

Levando em consideração as diferenças de nomenclaturas utilizadas nos questionários respondidos pelos profissionais, vale salientar que o objetivo principal deste estudo não foi o de verificar e nem analisar as nomenclaturas dos cursos de Educação Física, porém, faz-se necessário citar Sassaki (2006), o qual afirma que os valores e conceitos vão sendo substituídos por outros no campo de conhecimento das pessoas com deficiência, exigindo a utilização de novos termos nos diferentes contextos sociais e escolares.

Quanto à formação continuada dos docentes

Outra questão abordada neste estudo identificou o interesse dos participantes pela busca de conhecimento relacionado aos alunos com deficiência por meio da 
formação continuada. Assim, verificou-se que todos os profissionais realizaram cursos na área da Educação Especial (60\%), Atividade Física Adaptada (20\%) ou Educação Física Adaptada (20\%). Dentre eles, 40\% realizaram cursos de curta duração, sendo eles: Educação Especial Inclusiva; Pessoas com Necessidades Especiais; Atendimento às necessidades especiais/educação: métodos e técnicas de ensino/Educação Física Escolar; e, Educação Especial e Processos Inclusivos.

Os participantes ainda foram indagados sobre os estabelecimentos em que realizaram as suas respectivas especializações, sendo apontados os seguintes locais: "SOCIESC - Sociedade Educacional de Santa Catarina” (10\%), "IBPGE - Instituto Brasileiro de pós-graduação, pesquisa e extensão" (20\%), "Faculdade de Educação Física - São Carlos SP" (10\%), "IBPEX - Instituto Brasileiro de Pós-Graduação e Extensão" (10\%), "Inova - Instituto de Pós - graduação e Ensino Técnico" (10\%), "FAG - Faculdade Assis Gurgacz" (10\%), "FAESI - Faculdade de Ensino Superior de São Miguel do Iguaçu" (10\%), e, "ESAPE - Instituto de Estudos Avançados e Pós-Graduação / Faculdades Integradas do Vale do Ivaí" (20\%).

Mediante os resultados apresentados, Fonseca (1995) descreve que o professor de Educação Especial ${ }^{14}$ tem um campo muito vasto de funções profissionais: formação de professores; orientação e observação escolar; intervenção pedagógica com crianças deficientes; responsabilidade de casos de pequenos grupos; ações de apoio e encaminhamento; projetos experimentais; e, investigação precoce.
No que tange a formação continuada em Educação Especial, Fonseca (1995) ainda inteira que a aquisição de conhecimento é importante para os professores reconhecerem o processo das necessidades educacionais especiais do aluno, e concomitantemente, perceberem a importância dos mesmos no processo de aprendizagem. Além disto, é relevante que os professores desenvolvam suas atividades por meio de um contexto interdisciplinar e multidisciplinar, naturalmente apoiados por dados de investigação clínica e pedagógica, auxiliando na orientação dos pais quando houver necessidade.

A formação continuada do professor de Educação Física evidencia-se na necessidade de tornar-se um profissional de caráter amplo, com maior domínio e compreensão da realidade escolar atrelada a inclusão de alunos com deficiência, a fim de promover o desenvolvimento da consciência crítica que lhe permita interferir e transformar as condições da escola, da educação e da sociedade onde o aluno com deficiência está inserido (FREITAS, 2002).

Quanto à busca de conhecimentos em eventos científicos e formas de participação

Outra questão detalhada no instrumento de pesquisa remeteu-se a atual participação dos docentes em seminários, simpósios e congressos na área da Educação Especial, Atividade Física Adaptada ou áreas afins ligadas à pessoas com deficiência.

14 Modalidade de processo didático voltado às pessoas com deficiências, oferecida preferencialmente, na rede regular de ensino (LDB-9394/96). 
Dentre as respostas apresentadas, 30\% relataram uma participação/ano, 50\% mais que uma participação/ano e, 20\% uma participação esporádica (menos de uma vez/ano). Quanto à forma de participação nos eventos científicos, 90\% participam como ouvintes e $10 \%$ como apresentador de trabalhos.

Percebe-se que 50\% dos docentes preocuparam-se com as atualizações de conhecimento envolvendo pessoas com deficiência, pois sabe-se que a formação continuada dos professores deve estar alicerçada em informações fidedignas que aliem a experiência prática ao conhecimento científico metodologicamente dimensionado, pois estas coordenadas poderão favorecer a compreensão das práticas educacionais inclusivas e a superação dos tradicionais empirismos. Entretanto, considera-se relevante neste estudo o desinteresse dos docentes em partilhar seus conhecimentos e experiências de ensino por meio de apresentação de trabalhos em eventos científicos.

Betti (1996) destaca que muitos professores não pensam, agem ou falam como pesquisadores. Segundo o autor, a concepção docente é focar-se apenas na prática, ao passo que a visão do docente pesquisador foca-se nos processos epistêmicos, onde a linguagem da pesquisa e do conhecimento científico - formal e codificada - não é a mesma linguagem da prática profissional - cotidiana e informal (BETTI, 1996). Diante desta constatação, podemos inferir o diminuto interesse dos docentes avaliados em fazer ciência por meio de suas experiências cotidianas de ensino envolvendo alunos com deficiência.
Quantos aos cursos/palestras ministradas pelos docentes

Por fim, o instrumento buscou apontar se os profissionais já ministram cursos ou palestras com o tema envolvendo pessoas com deficiência. Revelou-se que 80\% dos docentes nunca disponibilizaram cursos/ palestras para a sociedade em geral, ao passo que $20 \%$ declararam ministrar cursos para alunos da rede Estadual - modalidade básica / Secretaria de Esportes, bem como para acadêmicos de Educação Física.

Faz-se importante entender que ministrar palestras não constitui-se obrigatória e nem enquadra-se em uma das funções específicas de ensino do professor, no entanto, vale ressaltar que ministrar cursos pode ser uma experiência muito interessante na vida de qualquer profissional, levando-se em conta o privilégio de ter o seu trabalho e seus conhecimentos expostos, cujas informações podem ajudar outros docentes a compartilhar das mesmas vivências profissionais.

Borges (1998, p. 12), comenta que a troca de experiências é de fundamental importância para a construção do saber, pois "na prática pedagógica e durante os cursos formativos, os professores constroem saberes que relacionam suas experiências de vida com as experiências de outros profissionais. Esses saberes se constituem um saber-fazer ou saberes que (in) formam suas ações e com base neles (...) estabelecem relações com o conhecimento já sistematizado."

Diante dos resultados apresentados, acredita-se que a formação inicial e continuada na área da Educação Física faz-se necessária, uma vez que são momentos destinados a discussões e esclarecimentos 
sobre os alunos com deficiência e suas experiências corporais, assim justificando a importância da educação pelo movimento que a disciplina Educação Física exerce enquanto disciplina escolar, cuja aplicação de conteúdos que visam o futuro desenvolvimento de cidadãos críticos, autônomos, responsáveis, reflexivos e conscientes de seus próprios atos.

\section{APONTAMENTOS FINAIS}

Neste estudo buscou-se identificar a formação inicial e continuada de docentes de Educação Física que atuam em modalidades de Ensino Especial. No que tange a formação inicial verificou-se que $80 \%$ dos professores concluíram sua formação em IES de ordem administrativa privada e que $100 \%$ deles apresentaram nas matrizes curriculares de seus cursos disciplinas que trataram da pessoa com deficiência e sua relação com a atividade física/esporte.

Em relação a formação continuada, constatou-se que $60 \%$ dos professores especializaram-se na área de Educação Especial, em contrapartida $40 \%$ fizeram cursos de curta duração nas áreas afins, sendo elas: Educação Física, Educação Especial Inclusiva, pessoas com necessidades especiais, atendimento às necessidades especiais/educação: métodos e técnicas de ensino/ Educação Física escolar e processos inclusivos.

Quanto à frequência de participação em eventos científicos que tratam de pessoas com deficiência (congressos, simpósios, jornadas), verificou-se o interesse dos docentes na atualização de seus saberes, uma vez que $50 \%$ deles relataram participar de eventos científicos mais de uma vez/ano.
Entretanto houve pouca representatividade no que tange a divulgação das experiências profissionais por meio de apresentação de trabalhos ou elaboração de artigos científicos, onde $10 \%$ da amostra mencionou sua participação como apresentador de trabalhos. Além disto, convém destacar que somente $20 \%$ dos docentes declararam ministrar cursos tratando de pessoas com deficiência para alunos da rede Estadual modalidade básica / Secretaria de Esportes para a sociedade, bem como para acadêmicos de Educação Física.

Acredita-se que os professores de Educação Física que atuam em modalidades de Educação Especial têm a possibilidade de explorar em escalas muito maiores o seu campo de atuação e construção de saber, por meio da continuidade de sua formação profissional e junto a isto, compartilhando seus conhecimentos e experiências profissionais com demais pessoas interessadas na área. Também faz-se necessário salientar que a disciplina de Educação Física é de grande importância nas modalidades de Ensino Especial, onde acredita-se que professores bem preparados poderão utilizarem-se da aplicação adequada de seus conteúdos, visando formar cidadãos críticos, autônomos, responsáveis, reflexivos e consciente de seus próprios atos, pois os alunos com deficiência merecem serem tratados com seriedade e profissionalismo por todos docentes, os quais devem estar preocupados com o bem-estar destes alunos, para que os mesmos também possam explorar suas potencialidades por meio da educação pelo movimento - a base da Educação Física.

Contudo, é aconselhável que os professores de Educação Física e que atuam na modalidade de Educação Especial, continuem buscando novos conhecimentos 
através de eventos científicos, palestras e cursos, não se esquecendo da produção de conhecimento através de publicações científicas.

Sugere-se novas pesquisas relacionadas à como os professores se sentem qualificados à esta atuação voltada a alunos com deficiência, e quais conhecimentos que a graduação e pós graduação devam oferecer para que eles e os futuros professores possa atuar com excelência.

\section{REFERÊNCIAS}

ARAÚJO, P. F. A educação física para pessoas portadoras de deficiências nas instituições especializadas de Campinas. Campinas/São Paulo: Unicamp, 1999.

BETTI, M. Por uma teoria da prática. Motus Corporis, (Edição Especial), v. 3, n. 2, 1996.

BRASIL. Lei de diretrizes e bases da educação nacional $n^{\circ}$ 9.394. 20 de dezembro de 1996. Estabelece as diretrizes e bases da educação nacional. Diário Oficial da República Federativa do Brasil. Brasília: Ministério da Educação, 1996

BORELLA, D. R.; Atividade Física Adaptada no contexto das matrizes curriculares dos cursos de Educação Física. Tese (Doutorado). São Carlos: UFSCar, 2010. BORGES, C. M. F. O professor de educação física e a construção do saber. 3.ed. São Paulo: Papirus, 1998.
DEMO, P. Ser professor é cuidar que o aluno aprenda. São Paulo: Mediação, 2004.

DENARI, F. E. Contrapontos da Educação Especial. São Carlos: Pedro \& João Editores, 2012.

E-MEC, SISTEMA DE REGULAÇÃO DO ENSINO SUPERIOR. Instituições de Educação Superior e Cursos Cadastrados. 2011. Disponível em < http://emec.mec.gov.br/> Acessado em 17 de outubro de 2011.

FONSECA, V. Introdução às Dificuldades de Aprendizagem. Rio Grande do Sul: Artes Médicas, 1995.

FREITAS, H. C. L. Formação de professores no Brasil: 10 anos de embate entre projetos de formação. Educação e Sociedade, v. 23, n. 80, p. 136-167, set. 2002.

PEDRINELLI, V. J. Conceituação e terminologia In: Educação física e desporto para pessoas portadoras de deficiências. Brasília, MEC-SEDES, SESI-DN, 1994.

SASSAKI, R. K. Terminologia sobre deficiência na era da inclusão. Revista Nacional de Reabilitação, São Paulo, ano 5, n. 24, jan./fev. 2006.

SILVA, R. F. Educação Física Adaptada no Brasil: da história à Inclusão Educacional. São Paulo: Phorte, 2008.

TARDIF, M. Saberes Docentes e Formação Profissional. São Paulo: Vozes, 2002. THOMAS, J, R.; NELSON, J. K. SILVERMAN, J. Métodos de pesquisa em atividade física.

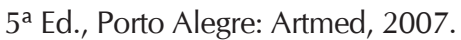


Ano XXV, n 40, junho/2013

INITIAL AND CONTINUING FORMATION OF PHYSICAL EDUCATION TEACHERS WORKING IN THE FORM OF SPECIAL EDUCATION

\begin{abstract}
This study aimed to identify the profile of physical education teachers working in the school environment in the form of Special Education, regarding the initial and continuing education related to persons with disabilities. We used exploratory and descriptive approach, quantitative. Given the results collected, it is believed that physical education teachers who work in terms of Special Education has the possibility to explore at much larger scales its field of operation and construction of knowledge, through the continuation of their training and with to it by sharing their professional knowledge and experience with others interested in this field.
\end{abstract}

Keywords: Formation; Teachers; Physical Education; People with Disabilities; Special Education.

Recebido em: fevereiro/2013

Aprovado em: maio/2013 